\title{
Bone Mineral Density and Vitamin D Values in Behçet's Disease
}

\author{
Behçet Hastalığında Kemik Mineral Dansitesi ve D Vitamini Değerleri
}

(D) Ayhan Kul, (D) Akın Erdal

Atatürk University Faculty of Medicine, Department Physical Medicine and Rehabilitation, Erzurum, Turkey

\section{Abstract}

Objective: It was aim to compare the bone mineral density (BMD) and 25-hydroxy vitamin $\mathrm{D}(25-\mathrm{OH}$ vitamin $\mathrm{D})$ values of the patients with Behçet's disease (BD) according to healthy population.

Materials and Methods: A total of 34 patients diagnosed with BD which was 15 males and 19 females (mean age: $35.1 \pm 8.6$ years; age range: 19 to 50 years), and 29 controls which was 12 males and 17 females (mean age: 36.9 \pm 9.2 years; age range: 21 to 51 years) were included in the study. The lumbar spine (L1-L4 total) measurements were made for the axial skeleton BMD values, and femur total and femur neck measurements were used for the appendicular skeleton BMD values.

Results: The patients' lumbar BMD values were significantly $(p<0.05)$ lower than those of the control group. However, the differences between femur total and femur neck values were not significant ( $p>0.05)$. There was no significant correlation between the $25-\mathrm{OH}$ vitamin $D$ values and the BMD values of the groups ( $p>0.05$ ).

Conclusion: Even though the BD has a subclinical inflammatory course, it can cause a reduction of BMD by affecting the bone metabolism. Thus, the patients' BMD values should be followed up, and when required vitamin D supplements should be administered to prevent the development of secondary osteoporosis.

Keywords: Behçet's disease, bone mineral density, 25-hydroxy vitamin D

\section{$\ddot{O z}$}

Amaç: Behçet hastalarında $(\mathrm{BH})$ kemik mineral dansisitesi (BMD) ve 25-hidroksi vitamin D (25-OH vitamin D) değerlerinin sağlıklı popülasyona göre karşılaştııılması amaçlanmıştır.

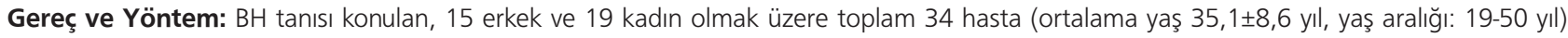

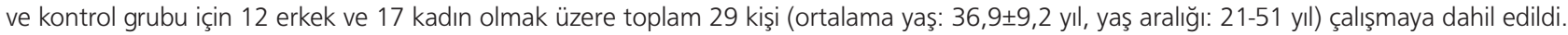
Aksiyel iskelet BMD değerleri için lumbar omurga (L1-L4 total) ve appendiküler iskelet BMD değerleri için femur total ve femur boynu ölçümleri yapılarak değerlendirildi.

Bulgular: Hastaların lumbar BMD değerleri kontrol grubuna göre anlamlı bir şekilde azalmışken $(p<0,05)$, femur total ve femur boynu değerlerinde ise anlamlı bir farklılık yoktu $(p>0,05)$. Grupların 25-OH vitamin D değerleri ile BMD değerleri arasında anlamlı bir ilişki bulunamadı $(p>0,05)$.

Sonuç: BH subklinik enflamasyon ile seyretse bile kemik metabolizması üzerine etki ederek BMD de azalmaya neden olabilir. Bu nedenle hastaların BMD yönü ile takip edilmesi ve gerektiğinde D vitamini takviyesi de yapılarak gelişebilecek bir sekonder osteoporoz oluşumu engellenebilir.

Anahtar kelimeler: Behçet hastalığı, kemik mineral dansitesi, 25-hidroksi vitamin D

\section{Introduction}

Behcet's disease $(B D)$ is a chronic multisystemic disorder with a clinical course involving unpredictable exacerbations and remissions. The spectrum of the disease involves ocular inflammation, mucocutaneous lesions, arthritis, neurological involvement, and other less frequent findings. The disease can affect people of both genders and all ages more specifically, ages between 20-30 years (1). The etiology and pathogenesis of BD is still not fully identified; however, it is thought that the onset of the disease is associated with an infectious agent, an immune mechanism, and genetic factors (2). However, the pathogenesis of the rheumatic features and the status of the bone metabolism is not known for this disease $(3,4)$. In $B D$, the inflammation has been suggested to be mediated by cytokines including tumor necrosis factor-alpha (TNF- $\alpha$ ), interleukin (IL)6, IL-18, and interferon- $\alpha$, which are produced by the Th1 
lymphocytes. These cytokines can induce bone resorption and can lead to increased bone catabolism and reduced bone mineral density (BMD). Chronicity, unclear etiology, and the medications used to treat the disorder can be the other causes of bone loss in BD patients. Reduction of BMD is a significant risk factor for osteoporotic fractures $(4,5)$.

Several studies have strongly supported the notion that vitamin D has immunoregulatory properties besides its functions as a mediator in calcium (Ca) and bone metabolism. The vitamin D receptors are commonly available on the cells of the immune system. The net effect of $1.25(\mathrm{OH}) 2 \mathrm{D} 3$ is the reduction of Th1 response in in vitro conditions through the dendritic cells, the CD4(+) T cells and the regulatory T cells (6). Since several recent studies have revealed the role of the Th1 polarization in the pathogenesis of $B D$, it is logical to investigate Vitamin $D$ levels among these patients (7).

In this study, we aimed to compare the BMD and 25-hydroxy vitamin $D(25-\mathrm{OH}$ vitamin $\mathrm{D})$ values of the $\mathrm{BD}$ patients to the normal healthy population's values and to investigate the relationship between these two parameters.

\section{Materials and Methods}

This study included patients who had presented to the Physical Medicine and Rehabilitation Department Outpatient Clinics of the Atatürk University Medical. All participants were informed about the protocol of the study and subsequently signed the written consent form that was prepared according to the Helsinki Declaration. This study was approved by the Ethical Committee of the Atatürk University Medical Faculty (05.05.2017/2; 17) The International Study Group (ISG) criteria were used for the diagnosis of $\mathrm{BD}$ patients regarding the selection of the patients. A total of 34 patients were included in the study (15 males and 19 females; average age 35.1 18.6 years, range: 19-50).

\section{Criteria of Inclusion to the Study}

Patients diagnosed according to the ISG criteria;

- Patients who have findings such as mucocutaneous lesions, or joint findings such as arthralgia and arthritis,

- Patients who had not been diagnosed with osteoporosis previously,

- Patients without any cause for a disease that can lead to secondary osteoporosis (endocrine and metabolic disorders, rheumatologic disorders, collagen tissue diseases, gastric surgery, malabsorption syndromes, liver and kidney diseases, and immobilization),

- Patients with no history of use of corticosteroids or other drugs that can lead to osteoporosis (except NSAIDs, paracetamol, colchicine).

\section{Criteria for Exclusion From the Study}

Patients with a history of using steroid and immunosuppressive drugs due to systemic involvement such as central nervous system involvement, vasculitis, gastrointestinal involvement, or pulmonary lesions.
Postmenopausal female patients; patients who have a history of using corticosteroids or other drugs that may lead to osteoporosis.

A total of 29 healthy individuals who were chosen among the hospital staff with no history of an inflammatory disorder were included in the study as the healthy control group (12 males, 17 females, average age 36.9 \pm 9.2 years, range: $21-51$ years). The exclusion criteria for the control group was the same as those of the study group.

The lumbar spine and left proximal femur BMD of 34 patients were evaluated using dual-energy X-ray absorptiometry (DEXA, Hologic QDR 2000). The lumbar spine (L1-L4 total) BMD values were measured for the axial skeleton, and the femur total and femur neck BMD values were used for the appendicular skeleton. The results were recorded in $\mathrm{g} / \mathrm{cm} 2$. The 34 patients were compared to 29 age and gender-matched controls.

The laboratory parameters [Ca, phosphate $(\mathrm{P})$, total alkaline phosphatase (ALP total)] were determined using the Beckman Coulter AU 5800 (Beckman Coulter, Inc, CA, USA) AutoAnalyzer with the spectrophotometric method. The $25-\mathrm{OH}$ vitamin $D$ levels were measured with chemiluminescence method using the Beckman Coulter UniCel Dxl 800 ((Beckman Coulter, Inc, CA, USA) device. Deoxypyridinoline (DPD; nM DPD/mM creatinine) was evaluated in the spot urine using the Siemens Immulite 2000 device (Siemens Diagnostic, Germany) with the chemiluminescence competitive immune assay method. From the peripheral blood, the erythrocyte sedimentation rate (ESR) was measured with the photometric method using test-1 (Alifax) device and the C-reactive protein (CRP) was quantitatively measured with the nephelometric method.

\section{Statistical Analysis}

The data were analyzed using the SPSS 20.0 program (SPSS, Chicago, IL, USA). The results were indicated as a mean \pm standard deviation. The parameters' compatibility with normal distribution was evaluated using the Kolmogorov-Smirnov test. For the comparison of the normally distributed parameters, the independent samples t-test (Student t-test), which is used for the comparison of the average of the numerical values obtained from two independent groups, was used. The non-normally distributed parameters were evaluated using the Mann-Whitney $\mathrm{U}$ test. The Pearson analysis was used for correlation analysis. $\mathrm{P}<0.05$ was considered statistically significant.

\section{Results}

The demographic, clinical, and laboratory findings of the study and control groups were presented in Table 1. Demographic variables such as age, gender, and body mass index (BMI) were similar in both groups ( $p>0.05)$. The differences between the two groups regarding several laboratory findings such as CRP, Ca, P, ALP, 25-OH vitamin D were not statistically significant $(p>0.05)$, whereas, the differences between the two groups regarding the ESR and DPD values were significant $(p<0.05)$. Both groups' $25-\mathrm{OH}$ vitamin $\mathrm{D}$ levels were below average (Table 1). 
The lumbar total, femur neck and femur total BMD values of the 34 patients and 29 control subjects were presented in Table 2 . The lumbar total BMD values were significantly lower among patients compared to the healthy controls $(p<0.05)$. The differences between the two groups regarding femur total and femur necks values were not statistically significant ( $p>0.05$ ) (Table 2).

The correlation between age, BMI, disease duration (month), ESR, CRP, DPD, and 25-OH vitamin D values with the lumbar total, femur neck, and femur total BMD values were presented in Table 3. This study did not find any significant correlation

\section{Table 1. The clinical and laboratory features of the patients with}

Behçet diseases and healthy controls

\begin{tabular}{|l|l|l|l|}
\hline & Patients & Controls & p value \\
\hline Sex (male/female) & $15 / 19$ & $12 / 17$ & 0.96 \\
\hline Age (years) & $35.1 \pm 8.6$ & $36.9 \pm 9.2$ & 0.433 \\
\hline $\begin{array}{l}\text { BMI }\left(\mathrm{kg} / \mathrm{m}^{2}\right) \\
\text { Disease duration (month) }\end{array}$ & $\begin{array}{l}25.9 \pm 5.77 \\
39.5 \pm 20.1\end{array}$ & $25.9 \pm 4.06$ & 0.95 \\
\hline ESR (mm/h) (min-max) & $11.8(2-67)$ & $6(2-20)$ & - \\
\hline CRP $(\mathrm{mg} / \mathrm{L})(\mathrm{min}-\mathrm{max})$ & $7.4(1.4-36)$ & $3.54(3-7.4)$ & 0.171 \\
\hline Calcium (mg/dL) & $9.3 \pm 0.3$ & $9.3 \pm 0.39$ & 0.96 \\
\hline Phosphate (mg/dL) & $3.53 \pm 0.59$ & $3.33 \pm 0.48$ & 0.16 \\
\hline ALP (U/L) & $68.2 \pm 19.4$ & $73 \pm 20.7$ & 0.35 \\
\hline 25-OH vitamin D (ng/mL) & $15.7 \pm 11$ & $12 \pm 5.69$ & 0.11 \\
\hline DPD (nM DPD/mM creatinine) & $6.77 \pm 2.2$ & $5.51 \pm 2.42$ & $0.03^{*}$ \\
\hline BMI: Body mass index, ESR:Erythe & &
\end{tabular}

BMI: Body mass index, ESR: Erythrocyte sedimentation rate, CRP: C-reactive protein, ALP: Alkaline phosphatase, DPD: Deoxypyridinoline, means \pm (standard deviation), median (min: minimum-max: maximum), " $p<0.05$ : Statistically significant difference between groups

Table 2. Bone mineral density values of the patients with Behçet

diseases and control subjects

\begin{tabular}{|l|l|l|l|}
\hline & Patients & Controls & p value \\
\hline Lumbar L1-L4 BMD $\left(\mathrm{g} / \mathrm{cm}^{2}\right)$ & $0.96 \pm 0.11$ & $1.02(0.10)$ & $0.02^{*}$ \\
\hline Femur neck BMD $\left(\mathrm{g} / \mathrm{cm}^{2}\right)$ & $0.82 \pm 0.11$ & $0.86(0.09)$ & 0.22 \\
\hline Femur total BMD $\left(\mathrm{g} / \mathrm{cm}^{2}\right)$ & $0.95 \pm 0.12$ & $0.96(0.09)$ & 0.73 \\
\hline
\end{tabular}

BMD: Bone mineral density, Means \pm standard deviation, ${ }^{p} p<0.05$ : Statistically significant difference between groups between the 25-OH vitamin D, ESR, CRP and DPD values and the BMD values of lumbar total, femur total and femur neck ( $p>0.05$ ) (Table 3). It was determined that there was a significant positive correlation between the age and BMI values and the patients lumbar total BMD values and that the duration of the disease was negatively correlated with the lumbar total BMD values $(p<0.05)$ (Table 3). Any significant difference was not found at levels of $25-\mathrm{OH}$ vitamin $\mathrm{D}$ between the control group and patients with active and inactive BD ( $p>0.05)$ (Table 4).

\section{Discussion}

BMD decreases either locally or generally among patients with chronic inflammatory rheumatic disorders such as rheumatoid arthritis (RA), systemic lupus erythematosus (SLE) and ankylosing spondylitis (AS). Several mechanisms aiming to explain the causes of reduced BMD in cases with chronic inflammation have been suggested. The studies have indicated that several osteoclastogenic proinflammatory cytokines such as IL-1, IL-6, TNF released from the inflammatory cells during the inflammatory process, modulate the release of receptor activator of nuclear factor kappa- $\beta$ ligand and osteoprotegerin, which regulate the osteogenetic and osteoclastic activities, thus, affecting the bone metabolism (8). It has been suggested that these proinflammatory osteoclastogenic cytokines also increase in $\mathrm{BD}$, thus inducing bone resorption, increasing bone destruction, and reducing $\operatorname{BMD}(4,5)$. The chronic inflammatory process, which can lead to the reduction of BMD among BD patients, is more prominent among BD patients with systemic involvement, compared to BD patients with mucocutaneous involvement. However, risk factors for osteoporosis and other causes of secondary osteoporosis can also play roles in the bone loss that is observed in chronic inflammatory diseases (8).

The number of studies evaluating the BMD and $25-\mathrm{OH}$ vitamin $D$ values in $B D$ is limited (9-11). Hence, we first aimed to investigate the BMD values, and then as the secondary aim, to determine the $25-\mathrm{OH}$ vitamin $\mathrm{D}$ values in $\mathrm{BD}$, and finally to compare these findings to determine whether there is a relationship between them.

Table 3. The correlation between demographic and laboratory values with Bone mineral density values

\begin{tabular}{|c|c|c|c|c|c|c|c|c|c|c|c|c|}
\hline & \multicolumn{6}{|c|}{ Patients } & \multicolumn{6}{|c|}{ Controls } \\
\hline & \multicolumn{2}{|c|}{ Lomber total BMD } & \multicolumn{2}{|c|}{ Femur neck BMD } & \multicolumn{2}{|c|}{ Femur total BMD } & \multicolumn{2}{|c|}{ Lomber total BMD } & \multicolumn{2}{|c|}{ Femur neck BMD } & \multicolumn{2}{|c|}{ Femur total BMD } \\
\hline & \multicolumn{2}{|c|}{$\left(\mathrm{g} / \mathrm{cm}^{2}\right)$} & \multicolumn{2}{|c|}{$\left(\mathrm{g} / \mathrm{cm}^{2}\right)$} & \multicolumn{2}{|c|}{$\left(\mathrm{g} / \mathrm{cm}^{2}\right)$} & \multicolumn{2}{|c|}{$\left(\mathrm{g} / \mathrm{cm}^{2}\right)$} & \multicolumn{2}{|c|}{$\left(\mathrm{g} / \mathrm{cm}^{2}\right)$} & \multicolumn{2}{|c|}{$\left(\mathrm{g} / \mathrm{cm}^{2}\right)$} \\
\hline & $\mathbf{p}$ & $r$ & $p$ & $r$ & $\mathbf{p}$ & $r$ & $p$ & $r$ & p & $r$ & $\mathbf{p}$ & $r$ \\
\hline Age & $0.046^{*}$ & 0.362 & 0.301 & 0.195 & 0.125 & 0.286 & 0.945 & 0.013 & 0.641 & -0.09 & 0.396 & -0.164 \\
\hline BMI & $0.049^{*}$ & 0.355 & 0.266 & 0.21 & 0.029 & 0.398 & 0.304 & 0.198 & 0.252 & 0.22 & 0.158 & 0.269 \\
\hline Disease duration & -0.253 & -0.212 & -0.167 & -0.259 & $0.034^{*}$ & -0.388 & - & - & - & - & - & - \\
\hline ESR & 0.141 & -0.271 & 0.27 & -0.208 & 0.47 & -0.137 & 0.225 & 0.232 & 0.712 & -0.072 & 0.86 & -0.034 \\
\hline CRP & 0.322 & -0.184 & 0.933 & 0.016 & 0.954 & 0.011 & 0.588 & 0.105 & 0.778 & 0.055 & 0.571 & 0.11 \\
\hline DPD & 0.328 & -0.182 & 0.149 & -0.27 & 0.156 & -0.266 & 0.134 & -0.291 & 0.054 & -0.368 & 0.135 & -0.29 \\
\hline $25-\mathrm{OH}$ vitamin D & 0.327 & -0.182 & 0.983 & 0.004 & 0.636 & 0.09 & 0.995 & -0.001 & 0.723 & -0.069 & 0.936 & -0.016 \\
\hline
\end{tabular}


Among the studies that evaluated BMD values of BD patients, only one study determined a significant reduction of lumbar spine total BMD (9). Two other studies indicated that they did not determine a significant difference between the lumbar spine total BMD and the femur BMD values of the study and healthy control groups $(10,11)$.

Kirnap et al. (9) determined that the lumbar spine BMD values were lower among BD patients compared to healthy controls, but that the proximal femur BMD values were not significantly different between the two groups. That study also determined that the CRP value, which is an indicator of active inflammation, was higher than normal. Also, the urine DPD value, which is a biochemical indicator of the bone cycle, was not significantly different between the BD patient group and the control group; however, the DPD level was determined to be higher in BD patient group (9).

In the study conducted by Bicer et al. (10) BD patients with systemic involvement were mostly excluded from the study. Contradictorily, the same study indicated that the evaluation of $\mathrm{BD}$ patients revealed patients with systemic involvement such as the involvement of the central nervous system, vasculitis, ocular, pulmonary, or gastrointestinal involvement. In that study, the lumbar total and femur (neck, trochanter, ward's triangle) BMD values of $\mathrm{BD}$ patients and healthy controls were not significantly different (10). Also, in the study conducted by Tekin et al. (11) BD patients' with systemic involvement were excluded from the study sample, and BD patients with mucocutaneous involvement were included. It was determined that only $20 \%$ of the BD patients had active arthritis. According to that study, the $\mathrm{BD}$ patients' and healthy controls' lumbar total and femur BMD values and the urine DPD values were not significantly different (11). Additionally, Bicer et al. (10) (mean duration of the disease: 6.68 years) and Tekin et al. (11) did not find any relationship between the duration of the disease and the BMD values. All three studies mentioned above had excluded patients with systemic involvement who had used drugs such as glucocorticoids and immunosuppressive that might have led to a reduction of BMD (9-11).

Our study similarly excluded patients who were using drugs such as glucocorticoids and immunosuppressive that can reduce BMD. Like Kirnap et al. (9) study our study determined that the femur neck and total femur BMD values were not affected by $\mathrm{BD}$, but the total lumbar BMD significantly decreased.

Table 4. Comparison of 25-hydroxy vitamin D levels in patients with active and inactive Behçet diseases and healthy controls

\begin{tabular}{|c|c|c|c|c|}
\hline & \multicolumn{2}{|c|}{ Patients } & \multirow{2}{*}{ Controls } & \multirow{2}{*}{ p } \\
\hline & Active $(n=18)$ & Inactive $(n=14)$ & & \\
\hline $25-\mathrm{OH}$ & \multirow{3}{*}{$15.1( \pm 6.8)$} & \multirow{3}{*}{$16.3( \pm 14.6)$} & \multirow{3}{*}{$12( \pm 5.6)$} & \\
\hline vitamin D & & & & ns \\
\hline$(\mathrm{ng} / \mathrm{mL})$ & & & & \\
\hline
\end{tabular}

means \pm (standard deviation), ns: Not significant ( $p>0.05)$ 25-OH: 25-hydroxy
However, our results are different from Kirnap et al. (9) study in that we found the CRP levels of the BD patients to be within normal limits, and the DPD levels in the spot urine test were significantly higher in the $\mathrm{BD}$ patients than those of the patients in the control group (9). This result may suggest that the total lumbar BMD can be affected even though the disease has a course with subclinical inflammation. Furthermore, the significantly increased DPD level may support the suggestion that the bone cycle might be affected in BD. That said, our study did not find any significant correlation between the DPD value and the lumbar total, femur neck and femur total BMD values. The reason why our study found reduced lumbar total BMD level in contrast to Bicer et al. (10) and Tekin et al. (11) studies might be that our study included several factors such as individual genetic characteristics, the activities of antioxidant metabolisms, lifestyle, and nutritional habits, and other related factors (sedentary lifestyle, Ca- and vitamin D-poor diet, proteinrich diet, alcohol and smoking) in addition to the presence of subclinical inflammation. In addition, since our study found that the duration of the disease (average: 39.5 months) was negatively correlated with the femur total BMD, which was different from Bicer et al. (10) and Tekin et al. (11) findings, it might have been determined that with increased duration of the disease, a significant reduction of femur total BMD values might have occurred. Our study found a positive correlation between age and lumbar total BMD values, similar to Bicer et al. (10). As is known, in literature, later ages is a risk factor for low BMD. It is also stated that BMD could reach peak bone mass until the age of 35 at the latest (12). In our study, average age of 35 might correspond to the time of peak bone mass formation. Therefore, positive correlation we have found might be related to peak bone mass. However, we think that it is difficult to reach a precise result owing to the restricted number of patients, and further studies are needed which include larger numbers of patients and BMD markers regarding bone formation and resorption. None of the three above-mentioned studies included 25-OH vitamin D measurements of the patients. The vitamin D deficiency among our study and control groups might have contributed to increased inflammatory activity and might indirectly have led to the reduction of lomber total BMD value (9-11).

Vitamin $\mathrm{D}$ is an important hormone involved in Ca homeostasis and bone cycle. Vitamin $D$ insufficiency is linked to several autoimmune diseases (13). For example, the deficiency of $25-\mathrm{OH}$ vitamin $\mathrm{D}$ was found to be related to the increase in disease activities of RA and SLE $(14,15)$. Since vitamin D has immunosuppressive functions, it has even been suggested to be used for the treatment of several autoimmune disorders (16). It was reported that, in AS patients, vitamin D deficiency could increase anti-inflammatory activity and indirectly cause osteoporosis (17). Do et al. (18) reported that vitamin D had suppressed the toll-like receptors (TLR) of BD patients in in vitro conditions and stated that vitamin $D$ might have a 
therapeutic value for the treatment of TLR2- and TLR4- induced inflammation, which has an important role in the pathogenesis of BD. Ibrahim et al. (19) found that patients with RA, SLE, $\mathrm{BD}$ and AS have $25-\mathrm{OH}$ vitamin D deficiency, and Nizar et al. (20) reported that vitamin $D$ levels were significantly lower among active BD patients (average: $20.4 \mathrm{ng} / \mathrm{mL}$ ) compared to healthy controls (average: $24.9 \mathrm{ng} / \mathrm{mL}$ ) and that this level was negatively correlated with the duration of the disease. Several other studies in the literature that investigated $25-\mathrm{OH}$ vitamin D levels found similar results $(19,20)$.

In our study, we found that the BD patients' $25-\mathrm{OH}$ vitamin $D$ levels were not significantly different from those of healthy controls. Also, in both groups, the BMD values were not significantly correlated with the $25-\mathrm{OH}$ vitamin D levels. In addition, any significant difference was not found at levels of $25-\mathrm{OH}$ vitamin $\mathrm{D}$ between the control group and patients with active and inactive BD (Table 4).

However, both groups had 25-OH vitamin D deficiency in our study. The $25-\mathrm{OH}$ vitamin $\mathrm{D}$ deficiency may be due to causes such as inadequate intake of $C a$ and vitamin $D$, malnutrition, insufficient exposure to sunlight, inadequate physical activity, smoking and alcohol consumption in the control group. Additionally, it has been reported that there has been an extensive vitamin $D$ deficiency in Turkey, together with several other tropical countries in the last 20 years (21-23). Therefore, the vitamin $D$ deficiency in the control group might have been affected by the geographical and environmental factors in our country. Regarding the BD group, the 25-OH Vitamin D deficiency might have been affected by the factors mentioned above, together with ongoing subclinical inflammation. Additionally, while active BD patients with systemic involvement were used in numerous studies investigating the $25-\mathrm{OH}$ vitamin $D$ levels in BD, our study only included BD patients with mucocutaneous involvement, and this may be the reason of the lack of a significant difference between the two groups.

\section{Study Limitations}

In this study, it has been found that in patients with BD have systemic involvement and patients taking immunosuppressive and steroid cannot be detected of BMD values can be a failure of evaluation of organ involvement and a failure of evaluation of the effect of the drugs.

\section{Conclusion}

In conclusion, even though BD has a subclinical inflammatory prognosis, it can affect the bone metabolism, and subsequently, lead to the reduction of BMD. Thus, the patients' BMD values should be monitored, and vitamin D supplements should be administered, if necessary, to prevent the development of secondary osteoporosis.

\section{Ethics}

Ethics Committee Approval: This study was approved by the Atatürk University, Clinical Research Ethics Committee (protocol no: 2017-2/17).

Informed Consent: Informed consent form was signed for all patients.

Peer-review: Externally peer-reviewed.

\section{Authorship Contributions}

Surgical and Medical Practices: A.K., A.E., Concept: A.K., A.E., Design: A.K., A.E., Data Collection or Processing: A.K., A.E., Analysis or Interpretation: A.K., A.E., Literature Search: A.K., A.E., Writing: A.K., A.E.

Conflict of Interest: No conflict of interest was declared by the authors.

Financial Disclosure: The authors declared that this study received no financial support.

\section{References}

1. Nair JR, Moots RJ. Behcet's disease. Clin Med (Lond) 2017;17:71-7.

2. Rokutanda R, Kishimoto M, Okada M. Update on the diagnosis and management of Behçet's disease. Open Access Rheumatol 2014;7:1-8.

3. Frikha F, Marzouk S, Kaddour N, Frigui M, Bahloul Z. Destructive arthritis in Behçet's disease: a report of eight cases and literature review. Int J Rheum Dis 2009;12:250-5.

4. Bicer A. Musculoskeletal Findings in Behcet's Disease. Patholog Res Int 2012;2012:653806.

5. Rachner TD, Khosla S, Hofbauer LC. Osteoporosis: now and the future. The Lancet 2011;377:1276-87.

6. Soilu-Hanninen M, Airas L, Mononen I, Heikkila A, Viljanen M, Hanninen A. 25-Hydroxyvitamin D levels in serum at the onset of multiple sclerosis. Multiple Sclerosis 2005;11:266-71.

7. Do JE, Kwon SY, Park S, Lee ES. Effects of vitamin D on expression of Toll-like receptors of monocytes from patients with Behcet's disease. Rheumatology (Oxford) 2008;47:8408

8. Humphrey MB, Nakmura MC. Pathogenesis of inflamationinduced bone loss. In: Lane NE, Jambrook P, editors. Osteoporosis and the osteoporosis of the rheumatic diseases. 1st ed. Mosby Elsevier, Philadelphia: 2006. p 249-64.

9. Kirnap M, Calis M, Kaya N, Muhtaroglu S. Is the Behçet's disease a risk factor for osteoporosis and is relation to cytokines? Bratisl Lek Listy 2010;111:340-4.

10. Bicer A, Tursen U, Kaya TI, Ozer C, Camdeviren H, Ikizoglu G, et al. Bone mineral density in patients with Behçet's disease. Rheumatol Int 2004:24:355-8.

11. Tekin NS, Ozdolap S, Sarikaya S, Esturk E, Gumustas S. Bone mineral density and bone turnover markers of patients with Behçet's disease. J Eur Acad Dermatol Venereol 2007;21:25-9.

12. Mora S, Gilsanz V. Establishment of peak bone mass. Endocrinol Metabol Clin N Am 2003;32:39-63.

13. Szodoray P, Nakken B, Gaal J, Jonsson R, Szegedi A, Zold E, et al. The complex role of vitamin $D$ in autoimmune diseases. Scand J Immunol 2008;68:261-9.

14. Thudi A, Yin S, Wandstrat AE, Li QZ, Olsen NJ. Vitamin D levels and disease status in Texas patients with systemic lupus erythematosus. Am J Med Sci 2008;35:99-104.

15. Cutolo M, Otsa K, Uprus M, Paolino S, Seriolo B. Vitamin D in rheumatoid arthritis. Autoimmun Rev 2007;7:59-64.

16. Arnson $Y$, Amital $H$, Shoenfeld $Y$. Vitamin $D$ and autoimmunity: new aetiological and therapeutic considerations. Ann Rheum Dis 2007:66:1137-42.

17. Mermerci Baskan B, Pekin Dogan Y, Sivas F, Bodur H, Ozoran $K$. The relation between osteoporosis and vitamin $D$ levels 
and disease activity in ankylosing spondylitis. Rheumatol Int 2010;30:375-81.

18. Do JE, Kwon SY, Park S, Lee ES. Effects of vitamin D on expression of Toll-like receptors of monocytes from patients with Behcet's disease. Rheumatology (Oxford) 2008;47:840-8.

19. Ibrahim MH, Bakheet MS, Abdel Sater KA, Abdel Shakoor M. Relationship between vitamin $D$ and disease activity in some rheumatic disease. Academic Journal of Medical Sciences 2013;2:52-6.

20. Nizar A Jassim, Noor Hassan A. Alrasool, Faiq I Gorial. Serum Vitamin D Level in Behcet's Disease: Single Center Study from Iraq. Am J Med Sci 2016;4:8-10.
21. Uçar F, Taşlipınar MY, Soydaş AÖ, Özcan N. Ankara Etlik intisas Eğitim Araştırma Hastanesi'ne Başvuran Hastalarda 25-OH Vitamin D Düzeyleri. Eur J Basic Med Sci 2012;2:12-5.

22. Van Schoor MN, Lips P. Worldwide vitamin D status. Best Pract Res Clin Endocrinol Metab 2011;25:671-80.

23. Mansoor S, Habib A, Ghani F, Fatmi Z, Badruddin S, Mansoor $S$, et al. Prevalence and significance of vitamin D deficiency and insufficiency among apparently healthy adults. Clin Biochem 2010;43:1431-5. 